\title{
A new award: the European Spine Journal Max Aebi Award for Clinical Sciences
}

\author{
R. Gunzburg ${ }^{1}$
}

Received: 2 December 2015/Revised: 2 December 2015/ Accepted: 2 December 2015/Published online: 14 December 2015

(C) Springer-Verlag Berlin Heidelberg 2015

The European Spine Journal has decided to honour one of its founders and past Editor-in-Chief, Prof. Dr. Max Aebi, by creating a new award bearing his name. This European Spine Journal Max Aebi Award for Clinical Sciences will be given on an annual basis for the best clinical paper published in the European Spine Journal over the period of 1 year. The amount will be 20,000 Euros. Each paper submitted to the Journal dealing with clinical issues qualifies automatically for this award as soon as it will have been published.

The award paper will be selected by an interdisciplinary committee from the Editorial and Advisory Board of the European Spine Journal supplemented by the Vice President of the Spine Society of Europe. The papers are being judged by five criteria: originality, soundness of materials and methods, results, quality of presentation and relevance.
This European Spine Journal Max Aebi Award for Clinical Sciences will be donated for the first time in 2016. The winning paper will be announced during the upcoming EuroSpine Annual Meeting. The authors will present their paper from the podium after which a certificate will be presented and handed over to the authors. ${ }^{1}$

Why an award for the best clinical paper already published in a journal? This award shall, in analogy with the European Spine Journal Grammer Award, reward the entire process of publishing a paper, which often involves a long story and strong discipline. After submitting a paper, it has to be defended against criticism from reviewers, not seldom resulting in a major rehaul of the document. This requires patience and endurance but usually leads to an improved version. We are thus looking forward to receiving many outstanding clinical papers from all over the world.
R. Gunzburg

robert@gunzburg.be

1 Cavell Spine Centre, Edith Cavell Clinic, Edith Cavell Street 32, 1180 Brussels, Belgium

\footnotetext{
$\overline{1}$ At least one of the authors must agree to attend the EuroSpine Annual Meeting at her/his own expenses in order to present the paper and receive the award.
} 